\title{
Curie point Depth and Heat Flow Analyses over Part of Bida Basin, North Central Nigeria using Aeromagnetic Data
}

\author{
Adewumi T. ${ }^{1}$, Salako K.A. ${ }^{2}$, Adediran O.S. ${ }^{3}$, Okwoko O.I. ${ }^{4}$, Sanusi Y. A. ${ }^{5}$ \\ ${ }^{1}$ Department of Physics, Faculty of Science, Federal University Lafia, Nasarawa State \\ ${ }^{2}$ Department of Physics, Federal University of Technology, Minna, Niger State \\ ${ }^{3}$ Department of Physics, University of Ilorin, Kwara State \\ ${ }^{4}$ Department of Physics, University of Abuja \\ ${ }^{5}$ Department of Physics, Usmanu Danfodiyo University, Sokoto
}

\begin{abstract}
This study attempt to estimate the Curie point depth (CPD) and heat flow using high resolution aeromagnetic data over part of Bida basin bounded with longitude $5^{\circ} 00^{\prime} \mathrm{E}-6^{\circ} 30^{\prime} \mathrm{E}$ and Latitude $8^{\circ} 30^{\prime} \mathrm{N}-9^{\circ} 30^{\prime} \mathrm{N}$ with an estimated total area of $18,150 \mathrm{~km}^{2}$. We subjected the total magnetic intensity field of the study area to regional/residual separation using polynomial fitting. We divided the residual map into sixteen overlapping spectral blocks. We obtained centroid depths (Zo) and depth to top of basement (Zt)got from the plot of log of power spectrum against wave number; the centroid depth ranges from $6.61 \mathrm{~km}$ to $20.30 \mathrm{~km}$ while the depth to top of basement ranges from $1.59 \mathrm{~km}$ to $6.38 \mathrm{~km}$. input parameter to calculate the curie depth $\left(\mathrm{Z}_{\mathrm{o}}\right)$. The CPD range from $10.88 \mathrm{~km}$ to $35.51 \mathrm{~km}$ with an average value of $23.22 \mathrm{~km}$. The CPD is deeper at the centre of the southern and eastern part of the study area which correspond to part of Pategi and part of Baro; and shallow at the northeastern and Northwestern part of the study area correspond to part of Mokwa and part of Bida. The geothermal gradients for the sixteen blocks range from $16.33{ }^{\circ} \mathrm{Ckm}^{-1}$ at the centre of the southern region of the area to $53.30^{\circ} \mathrm{Ckm}^{-1}$ at the northeastern and north western region of the study area with an average of $28.98{ }^{\circ} \mathrm{Ckm}^{-1}$. While the heat flow to range from $40.99 \mathrm{mWm}^{-1}$ to 133.80 $\mathrm{mWm}^{-1}$ with an average value of $76.19 \mathrm{mWm}^{-2}$. It can therefore be deduced from this study that the Southeastern, southwestern, and the northwestern part of the study area might be a good indicator of geothermal energy potential with minimum CPD, maximum geothermal gradient and heat flow since demagnetized rocks confirm a hot rock quantity in the crust that can be harnessed for geothermal energy exploitation.
\end{abstract}

Keywords: Aeromagnetic data; Curie depth; geothermal energy; Heat flow; Polynomial

Corresponding email: taiwo.adewumi@fulafiaphysics.org,tydon4real@yahoo.co.uk

\section{INTRODUCTION}

The high resolution aeromagnetic data over part of Bida Basin has been analyzed and interpreted quantitatively with the aim of estimating the Curie point depth and the heat flow of the study area based on a reconnaissance for geothermal energy. The Curie point (bottom of magnetic source) is the point in the earth crust at about the temperature of $580{ }^{\circ} \mathrm{C}$ for magnetite under atmospheric pressure where magnetic properties of rocks disappears and magnetic minerals show paramagnetic susceptibility (Khojamli et al., 2016). The deepness at which temperature reaches the Curie point is assumed to be the bottom of the magnetized bodies in the earth crust. Depending on the geology and rock mineral contents, Curie point temperature varies from area to area. It is therefore normal to expect minimum Curie point depth (CPD) at the regions which have geothermal potential, young volcanisms and a thin crust (Aydın \& Oksum, 2010). The assessment of the disparities in the CPD of a particular region can give a preliminary and appreciated information about the area temperature distribution at depth and the geothermal energy potential of the subsurface (Tselentis, 1991).

In some part of Nigeria, there are geological and geophysical evidences and presence of warm spring in the southwest (Ikogosi) and hot spring in the North central (Wikki) which have a good indicator for geothermal potential energy. It is therefore a necessity for this present study to be carried out using the aeromagnetic 
data of part of Bida Basin based on a reconnaissance survey to assess the geothermal energy potential from the result of CPD and heat flow got from the area.

\section{Location and the Geological setting of the Study Area}

The study area (Fig.1) is part of Bida Basin bounded by longitude $5^{\circ} 00^{\prime} \mathrm{E}-6^{\circ} 30^{\prime} \mathrm{E}$ and latitude $8^{\circ} 30^{\prime} \mathrm{N}$ $9^{\circ} 30^{\prime} \mathrm{N}$ with an estimated total area of $18,150 \mathrm{~km}^{2}$. The Bida Basin is an intracratonic sedimentary basin that trends NW-SE direction and spreads from Niger State to areas to some extent beyond Kogi State in the southern part. It's surrounded in the northeastern and southwestern by the crystalline rocks though it combines with Anambra and Sokoto basins in sedimentary fill comprising post orogenic molasse facies and a few thin unfolded marine sediments (Adeleye, 1974). The basin is a gently down warped trough whose genesis may be closely connected with the Santonian orogenic movements of south-east Nigeria and the Benue valley, nearby (Fig.2).

The Initial geophysical work carried out using gravity data of the Bida Basin give the deeper sedimentary thickness of a about $3.5 \mathrm{~km}$ in the central region (Ojo, 1984). Even though the hydrocarbon potential of the basin has evaluated with seismic and the basin remains undrilled, both ground and aeromagnetic studies by several researchers have revealed the basin configuration (Adeniyi, 1985; Udensi \& Osazuwa, 2004). Recently, the depth analysis carried out in the basin discloses an average depth to top of basement rocks to be $3.4 \mathrm{~km}$ with the thickness of sediments up to $4.7 \mathrm{~km}$ in the central and southern parts of the basin (Udensi \& Osazuwa, 2004). At large, thickness of sediment decreases smoothly from the central portion to the flanks of the basin. Geophysically and geologically, the basin has witness little or no geothermal studies. This necessitate this present work to have a good understanding and provide preliminary information of geothermal energy potential of the area.

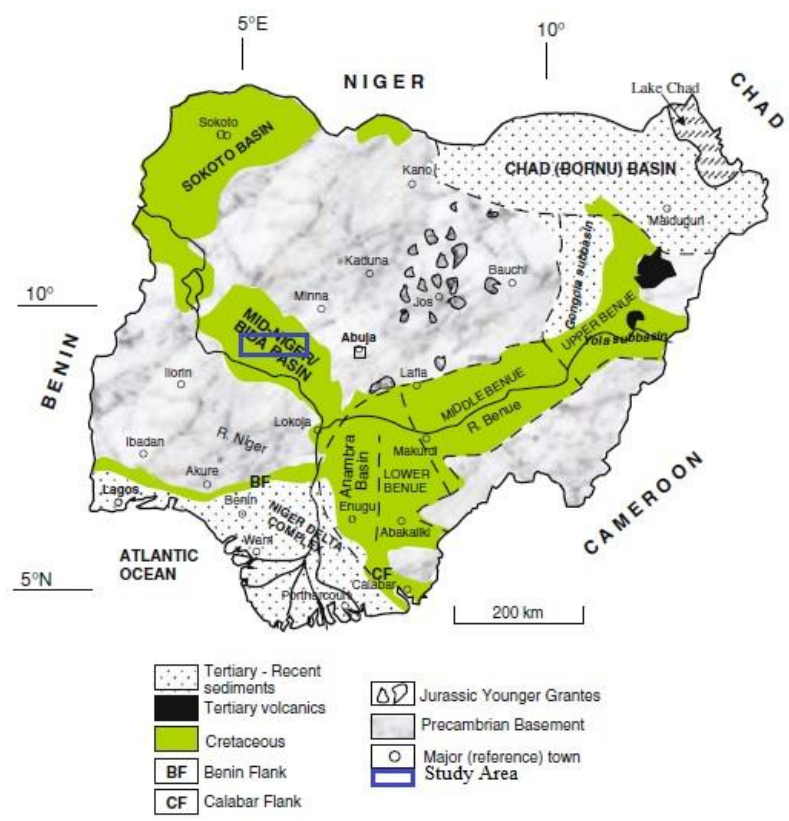

Fig. 1. Geologic drawing of Nigeria displaying the position of the study area (Obaje, 2009). 


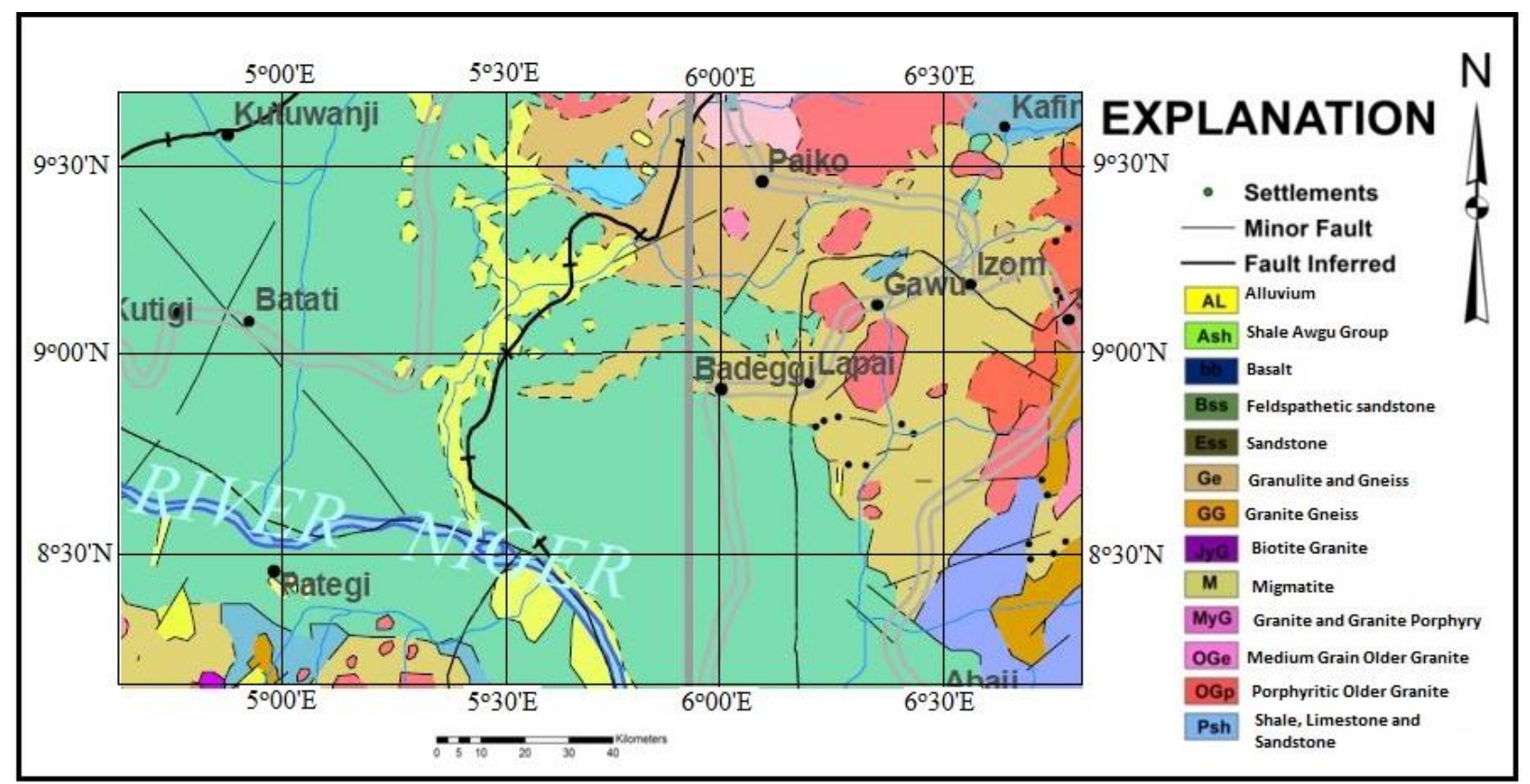

Fig. 2. Geological map of the Study Area (Nigeria Geological Survey Agency, 2009)

\section{DATA \& METHODOLOGY}

\section{Data}

The aeromagnetic data used in this study was procured from Nigeria Geological Survey Agency. The data was part of the high resolution aeromagnetic data got from the nationwide airborne survey carried between the year 2004 -2009. Fugro Airborne Survey Limited carried this survey out for Nigeria Geological Survey Agency (NGSA). They carried the survey out with the following details;
Terrain clearance
$=80 \mathrm{~m}$
Line spacing
Nominal tie-line spacing
$=\quad 500 \mathrm{~m}$
The flight line and tie-line trends
$=2 \mathrm{~km}$.
$=\quad 135$ and $45^{\circ}$.

\section{Methods}

This study used the spectral analysis of the aeromagnetic data to determine the CPD of the study area. Spector and Grant (1970) explained the spectral analysis method they used which to determine the depth to top of magnetic four-sided prism $\left(\mathrm{Z}_{\mathrm{t}}\right)$ from the gradient of the $\log$ of power spectrum. Bhattacharyya and Leu (1977); Bhattacharyya and Leu (1975) from the idea of Spector and Grant (1970) calculated the depth to the centroid of the magnetized source rock (Zo). Okubo, Graf, Hansen, Ogawa, and Tsu (1985) combined and expanded the idea from Spector and Grant (1970), Bhattacharyya and Leu (1975), and Bhattacharyya and Leu (1977) to develop the method to determine the bottom depth of magnetized bodies $\left(\mathrm{Z}_{\mathrm{b}}\right)$. If the degree at which a magnetic body of a sst of 2D bodies is absolutely random and uncorrelated, the circular average of the power density spectra of the total field anomaly, p (k), could be expressed as follows (Blakely, 1996; Stampolidis, Kane, Tsokas, \& Tsourlos, 2005):

$$
P(k)=A_{1} e^{-2|k| Z_{t}}\left(1-e^{-|k|\left(Z_{z}-Z_{t}\right)}\right)^{2}
$$

where $A_{1}$ is a constant and $Z_{t}$ and $Z_{b}$ denote the depths to the top and bottom of the magnetic body, respectively. $\mathrm{k}$ indicates the wave number of the magnetic field. 
According to Okubo et al. (1985), CPD $\left(\mathrm{Z}_{\mathrm{b}}\right)$ can be achieved in two stages. First of all, the centroid depth $\left(\mathrm{Z}_{0}\right)$ of the inmost magnetic source is appraised from the gradient of the lengthiest wavelength part of the spectrum divided by the wave number using the following equation (Nwankwo \& Shehu, 2015):

$$
\operatorname{In}\left(\frac{P(k)^{1 / 2}}{k}\right)=A|k| Z_{o}
$$

where $\mathrm{P}(\mathrm{k})$ is the power density spectrum, and A signifies a constant.

Secondly, the uppermost depth to the magnetic body is also derived from the gradient of high wave number portion of the power spectrum as follows:

$$
\operatorname{In}\left(P(k)^{1 / 2}\right)-B-|k| Z_{t}
$$

where $\mathrm{B}$ is a constant.

The depth to the bottom of the magnetized body is therefore then got as follows;

$$
\mathrm{Z}_{\mathrm{b}}=2 \mathrm{Z}_{0}-\mathrm{Z}_{\mathrm{t}}
$$

Where $Z_{b}$ is the depth to the bottom of magnetized body, $Z_{o}$ is the centroid depth and $Z_{t}$ is the depth to top of the magnetized body.

As discussed in the methods above, CPD is calculated in three phases: (i) dividing the residual of the TMI map into overlapping blocks, (ii) computing the logarithm of power spectrum for each blocks, the centroid depth and depth to top of the magnetized body is got and (iii) using $\mathrm{Z}_{\mathrm{b}}=2 \mathrm{Z}_{0}-\mathrm{Z}_{\mathrm{t}}$ the basal depth is calculated.

Having calculated the CPD, the heat flow is therefore calculated from the equation as follow;

$$
q=k \frac{\partial T}{\partial Z}
$$

Where $\mathrm{q}$ is the heat flow, $\mathrm{k}$ is the thermal conductivity and $d T / d Z$ is the thermal gradient.

According to Tanaka, Okubo, and Matsubayashi (1999); Stampolidis et al. (2005), the Curie depth is related with the Curie temperature $\left(580^{\circ} \mathrm{C}\right)$, the vertical direction of temperature variation and the constant thermal gradient were assumed. The geothermal gradient (dT/dz) between the Earth's surface and the Curie point depth $(\mathrm{Zb})$ is defined using the relation as follow;

$$
\frac{d T}{d z}=\theta_{c} / Z_{b}
$$

$d T / d Z$ is the thermal gradient, $\theta c\left(580^{\circ}\right)$ is the Curie temperature and $Z_{b}$ is the Curie depth

\section{DATA PROCESSING AND ANALYSIS}

Six aeromagnetic data as discussed above were procured from NGSA in $1 / 2^{\circ}$ by $1 / 2^{\circ}(55 \times 55 \mathrm{~km})$ per sheets. The data which were in separate sheets were assemble and knitted together to produce the composite map (TMI) of the study area (Fig.3). The actual value of the data has been reduced by 33,000nT for the purpose of handling. So in order to get the actual value at any point, a total value of $33,000 \mathrm{nT}$ must be added back to the data. The data had been corrected based on the International Geomagnetic Reference Field (IGRF) of epoch date January 1, 2005. The total magnetic intensity map was subjected to regional/residual separation using polynomial fitting (order one) for further processing. The residual map (Fig. 4) was divided into fourteen overlapping blocks for the spectral analysis. The blocks were in different 
sizes; block A - F in 55 x $55 \mathrm{~km}$, block $\mathrm{G}-\mathrm{I}$ in 55 x $110 \mathrm{~km}$, block $\mathrm{J}-\mathrm{L}$ in 165 x $37 \mathrm{~km}$, block $\mathrm{M}-\mathrm{N}$ in $82.5 \times 110 \mathrm{~km}$ and block $\mathrm{O}-\mathrm{P}$ in $165 \times 110 \mathrm{~km}$. It is generally admitted that the utilization of a small window width may be a fundamental error in the application of spectral methods for aeromagnetic interpretation (Nwankwo \& Shehu, 2015). Spectral analysis was performed on each overlapping blocks. The data got from the spectral in csv format were exported into Microsoft excel where the data for wave number and log of energy spectrum were extracted for plotting. The data were plotted using a program written in Matlab to deduce the centroid depth from the slope of the long wavelength (Zo) and the depth to top of the magnetized body $(\mathrm{Zt})$.

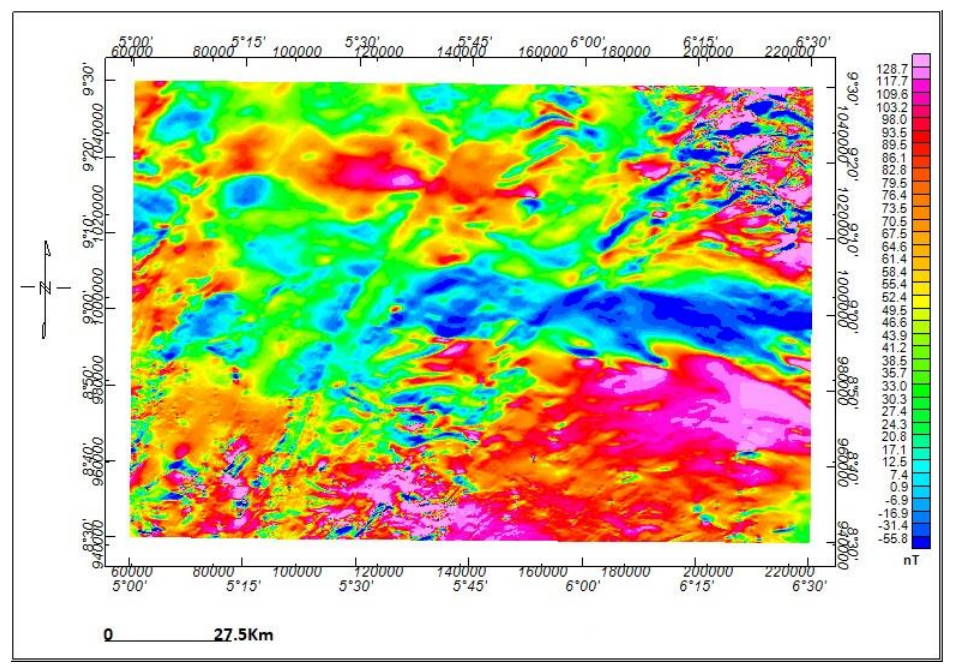

Fig. 3. Total magnetic intensity map of the study area

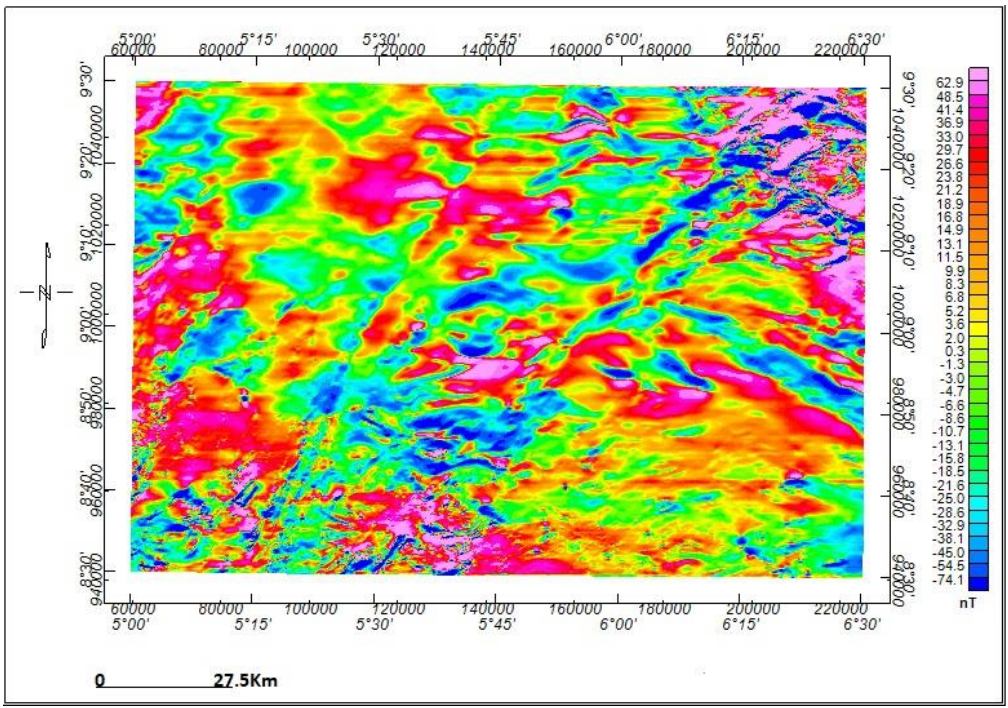

Fig. 4. Residual of the total magnetic intensity Map

\section{RESULT AND DISCUSSION}

The depth to a centroid for the sixteen blocks (Fig. 5a-b) were calculated from the gradient of the lengthiest wavelength part of the spectrum divided by the wave number using equation 2 . The centroid depth ranges from $6.61 \mathrm{~km}$ to $20.30 \mathrm{~km}$ (table 1). Figure 6a shows that the depth to centroid of the magnetized body is 
the minimum at the northeastern part of the study area which corresponds to part of Bida and maximum at the southern part of the study area which also corresponds to part of Pategi. Using equation 3, the utmost depth of magnetic source was estimated from the gradient of high wave number portion of the power spectrum (Fig. $5 \mathrm{c}-\mathrm{d}$ ). Table 1 shows that the depth to top of magnetic source varies between $1.56 \mathrm{~km}$ and $6.38 \mathrm{~km}$. The highest depth to top of magnetic source is pronounced at the extreme southern and extreme northern part of the study area which corresponds to part of Pategi and part of Mokwa respectively (Fig. $6 \mathrm{~b})$. The maximum depth to top of the magnetized body of $4.5 \mathrm{~km}$ at the southern part of the study area agrees with Udensi and Osazuwa (2004) and Okwokwo, Adetona, Adewumi, and Adeniran (2018).
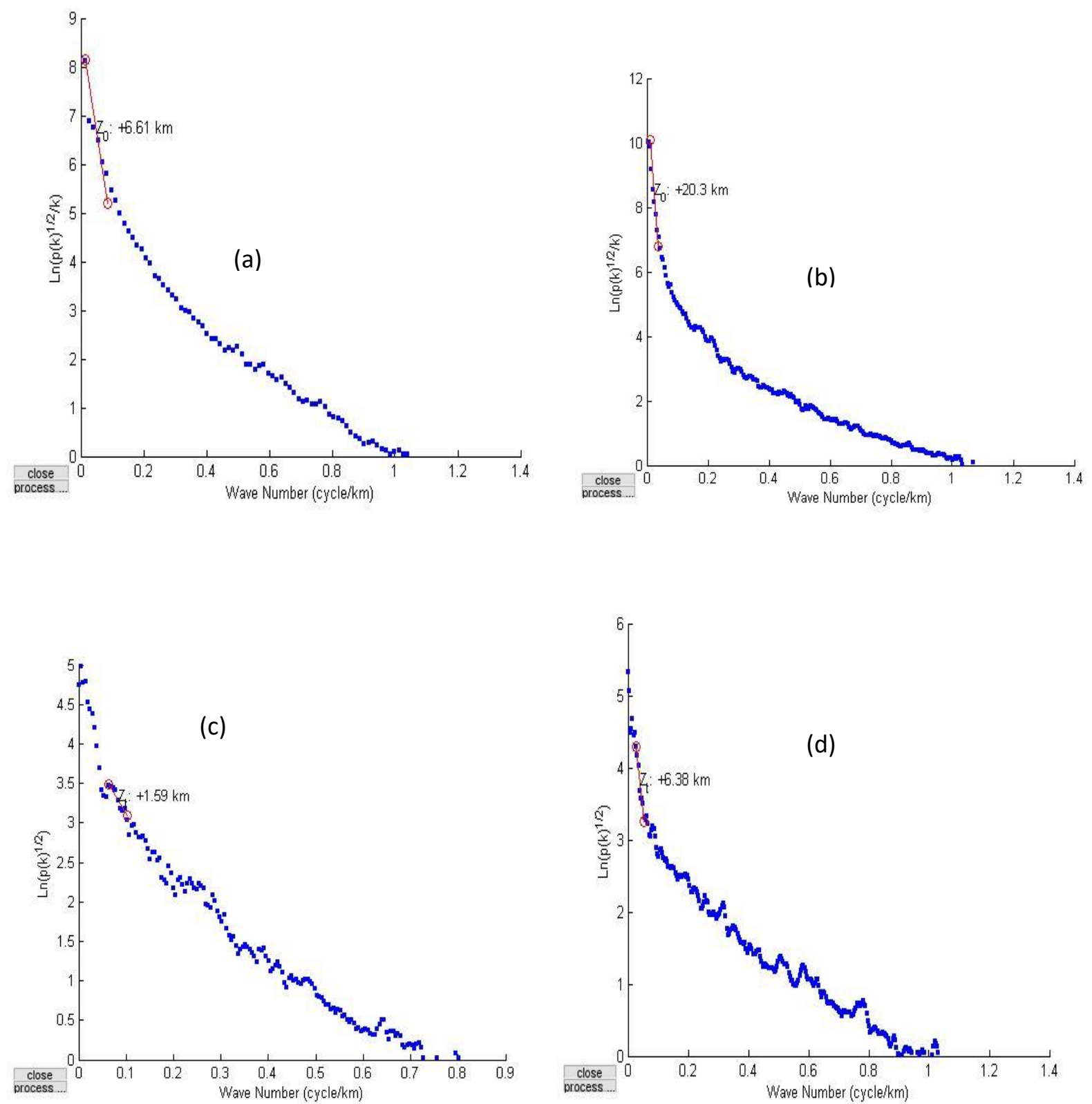

Fig. 5. (a) Azimuthally average power spectral plots for block $C$ showing minimum $Z o=6.61 \mathrm{~km}$; (b) maximum $\mathrm{Zo}=20.30 \mathrm{~km}$ for block $\mathrm{L}$, (c) minimum $\mathrm{Zt}=1.59 \mathrm{~km}$ for block $\mathrm{K}$; and (d) maximum $\mathrm{Zt}=6.28$ $\mathrm{km}$ for block $\mathrm{O}$. 
The depth to centroid (Zo) and utmost depth of magnetic boundary was used as an input parameter to determine the bottommost depth of magnetic bodies (CPD) using equation 4. Table 1 reveals that the CPD ranges from $10.88 \mathrm{~km}$ to $35.51 \mathrm{~km}$ with an average value of $23.22 \mathrm{~km}$. The CPD is deeper at the centre of the southern and eastern part of the study area which correspond to part of Pategi and part of Baro respectively; and shallow at the northeastern and Northwestern part of the study area agree to part of Mokwa and part of Bida, respectively (Fig. 6c).

\begin{tabular}{cccccccc}
\hline Blocks & $\begin{array}{c}\text { Long } \\
(\text { Deg. })\end{array}$ & $\begin{array}{c}\text { Lat. } \\
(\text { Deg. })\end{array}$ & $\begin{array}{c}\text { Depth to } \\
\text { Centroid }(\mathrm{km})\end{array}$ & $\begin{array}{c}\text { Depth to top } \\
(\mathrm{km})\end{array}$ & $\begin{array}{c}\text { Curie Depth } \\
(\mathrm{km})\end{array}$ & $\begin{array}{c}\text { Geothermal } \\
\text { gradient. } \\
{ }^{\circ} \mathrm{C} / \mathrm{Km}\end{array}$ & $\begin{array}{c}\text { Heat flow. } \\
\mathrm{mWm}^{-2}\end{array}$ \\
\hline A & 5.25 & 9.25 & 7.87 & 4.22 & 11.52 & 50.35 & 126.27 \\
B & 5.75 & 9.25 & 10.70 & 1.92 & 19.48 & 29.77 & 74.72 \\
C & 6.25 & 9.25 & 6.61 & 2.34 & 10.88 & 53.30 & 133.80 \\
D & 5.25 & 8.75 & 9.33 & 3.20 & 15.46 & 37.51 & 94.15 \\
E & 6.75 & 8.75 & 10.60 & 1.87 & 19.33 & 30.00 & 75.31 \\
F & 6.25 & 8.75 & 7.65 & 2.27 & 13.03 & 44.51 & 111.72 \\
G & 5.25 & 9.00 & 12.50 & 2.61 & 22.39 & 25.90 & 65.02 \\
H & 5.75 & 9.00 & 11.70 & 4.11 & 19.29 & 30.06 & 75.46 \\
I & 6.25 & 9.00 & 11.90 & 1.80 & 22.00 & 26.36 & 66.17 \\
J & 5.75 & 9.33 & 20.00 & 4.49 & 35.51 & 16.33 & 40.99 \\
K & 5.75 & 8.99 & 15.40 & 1.59 & 29.21 & 19.85 & 49.83 \\
L & 5.75 & 8.66 & 20.30 & 5.11 & 35.49 & 16.34 & 41.02 \\
M & 5.37 & 9.00 & 10.50 & 1.90 & 19.1 & 30.36 & 76.21 \\
N & 6.12 & 9.00 & 18.20 & 1.56 & 34.84 & 16.64 & 41.78 \\
O & 5.75 & 9.25 & 17.80 & 6.28 & 29.32 & 19.78 & 49.65 \\
P & 5.75 & 8.75 & 18.70 & 2.72 & 34.68 & 16.72 & 41.97 \\
\hline
\end{tabular}

Table 1. Estimated CPD, geothermal gradients and heat flow depth for the 16 blocks in the study area

The Curie temperature approximately $580^{\circ} \mathrm{c}$ was divided by the estimated CPDs to give the geothermal gradients for the sixteen blocks which range from $16.33{ }^{\circ} \mathrm{Ckm}^{-1}$ at the centre of the southern region of the area to $53.30{ }^{\circ} \mathrm{Ckm}^{-1}$ at the northeastern and north western region of the study area with average of 28.98 ${ }^{\circ} \mathrm{Ckm}^{-1}$ (Fig. 6d). Table 1 gives the heat flow to range from $40.99 \mathrm{mWm}^{-1}$ to $133.80 \mathrm{mWm}^{-1}$ with an average value of $76.19 \mathrm{mWm}^{-2}$. The heat flow was estimated by multiplying the geothermal gradient estimated by coefficient of thermal gradient of $2.51 \mathrm{Wm}^{-1} \mathrm{C}^{-1}$. The CPD, geothermal gradient and heat flow estimated from this present study agrees with Nwankwo and Shehu (2015). 
Adewumi T, Salako K.A, Adediran O.S., Okwoko O.I., Sanusi Y. A /JEEE Vol. 8 No. 1/2019

(a)

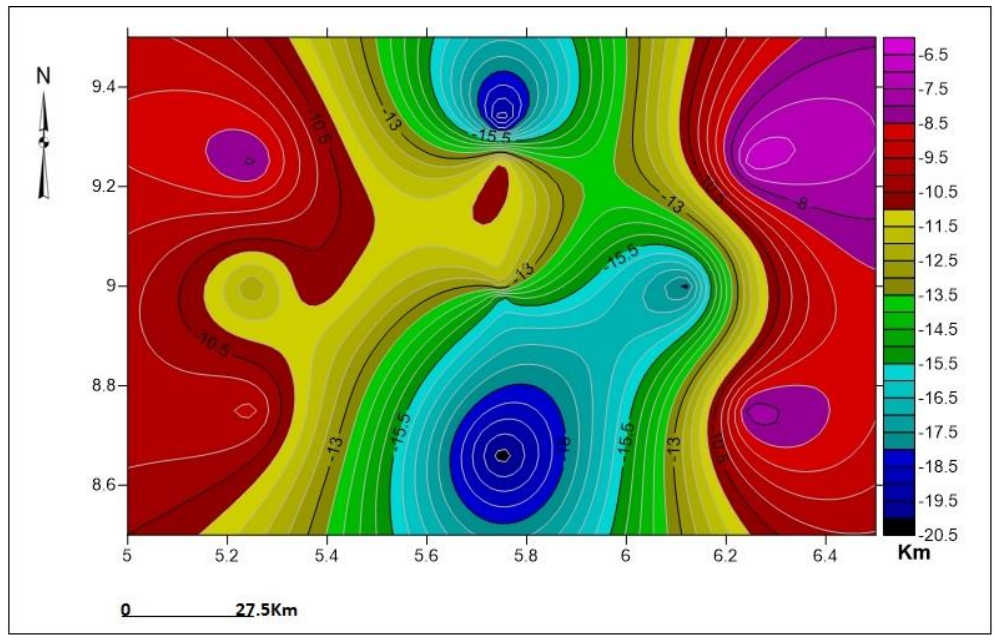

(b)

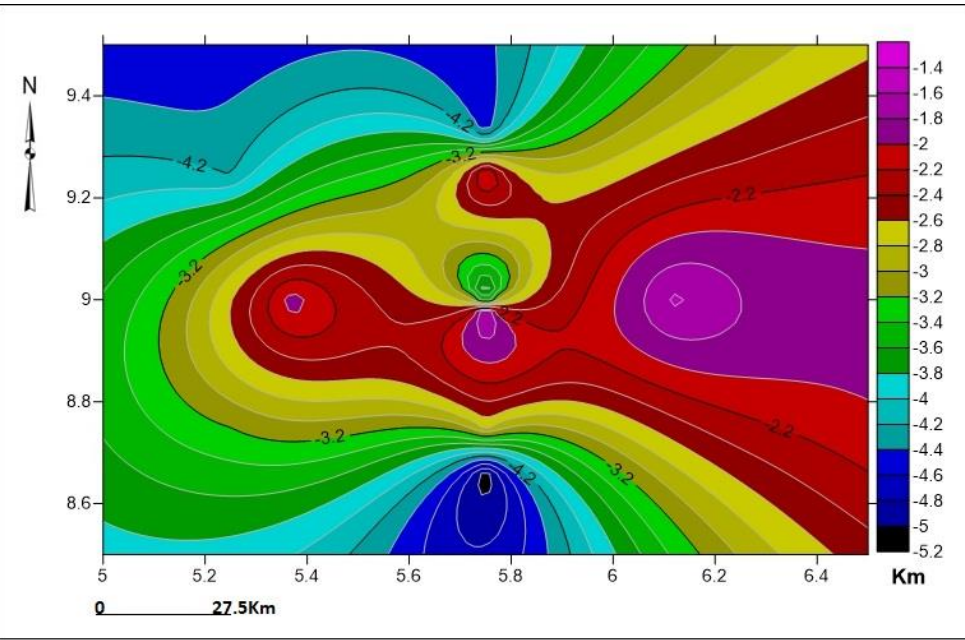

(c)




(d)

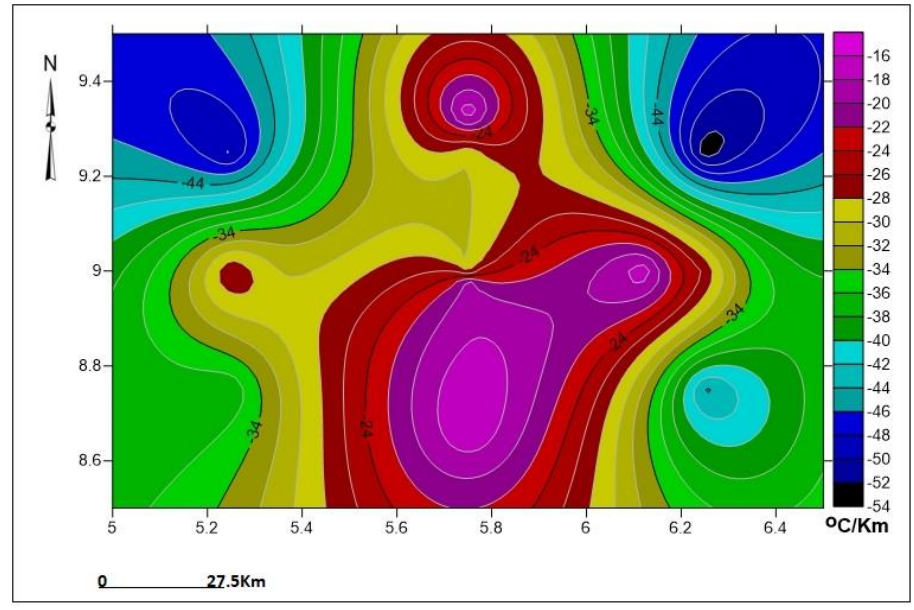

(e)

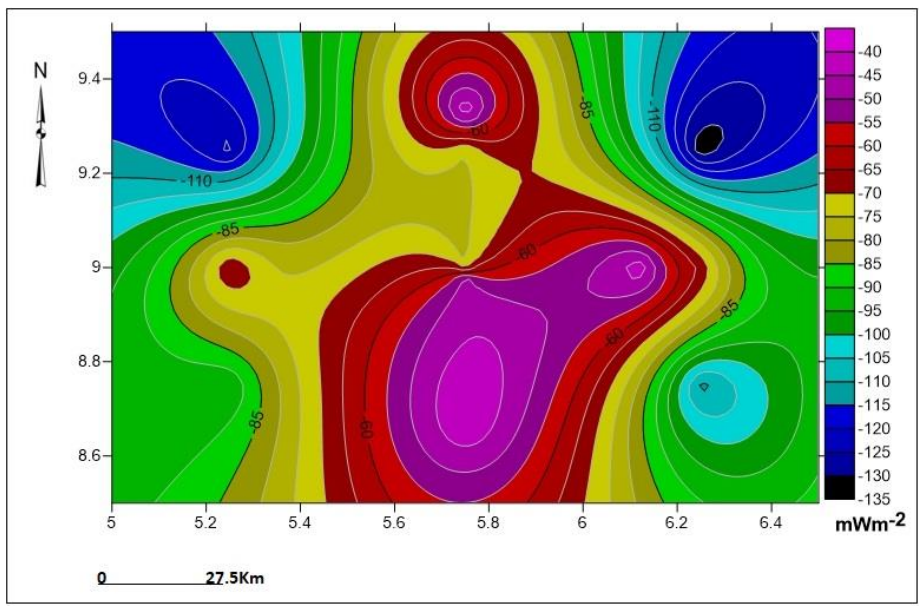

Fig. 6: (a) is the contour map of the depth to centroid of the magnetized body in km (b) the contour map of depth to top of magnetic boundary in $\mathrm{km}$ (c) the depth to bottom of magnetized body (CPD) in $\mathrm{km}$ (d) the contour map of geothermal gradient in ${ }^{\circ} \mathrm{Ckm}^{-1}$ and (e) the contour map of the heat flow of the study area in $\mathrm{mWm}^{-2}$.

The CPD intensely differs according to the geological situations (Ross, Blakely, \& Zoback, 2006). The CPDs at volcanic and geothermal areas are shallower than $10 \mathrm{~km}$ (Obande, Lawal, \& Ahmed, 2014). Jessop, Hobart, and Sclater (1976) explained that heat flow of about $80-100 \mathrm{MW} / \mathrm{m}^{2}$ indicates geothermal anomalous conditions. Objectively, measurement of heat flow determine the quantity of heat energy being vanished by naocess. High heat loss anomalies usually concur with the structural trend or areas with thermal manifestations (Ochieng, 2014). In this present study, it can therefore be inferred that some part of the study area such as; the southeastern, southwestern, and the northwestern part of the study area are good indicator of geothermal energy potential with shallow CPD, high geothermal gradient and heat flow.

\section{CONCLUSION}

This study present the result of CPD, geothermal gradient and heat flow from the spectral analysis of high resolution aeromagnetic data of part of Bida Basin, Nigeria. The CPD range from $10.88 \mathrm{~km}$ to $35.51 \mathrm{~km}$ with an average value of $23.22 \mathrm{~km}$. The CPD is deeper at the centre of the southern and eastern part of the study area which correspond to part of Pategi and part of Baro respectively; and shallow at the northeastern and Northwestern part of the study area correspond to part of Mokwa and part of Bida respectively. The geothermal gradients for the sixteen blocks range from $16.33{ }^{\circ} \mathrm{Ckm}^{-1}$ at the centre of the southern region of 
Adewumi T, Salako K.A, Adediran O.S., Okwoko O.I., Sanusi Y. A /JEEE Vol. 8 No. 1/2019

the area to $53.30{ }^{\circ} \mathrm{Ckm}^{-1}$ at the northeastern and north western region of the study area with average of $28.98{ }^{\circ} \mathrm{Ckm}^{-1}$. While the heat flow to range from $40.99 \mathrm{mWm}^{-1}$ to $133.80 \mathrm{mWm}^{-1}$ with an average value of $76.19 \mathrm{mWm}^{-2}$. It can therefore deduced from this study that the southeastern, southwestern, and the northwestern part of the study area might be a good indicator of geothermal energy potential with near surface CPD, high geothermal gradient and heat flow since loss of magnetic properties in rocks confirm the presence of a hot rock mass in the crust that can be harnessed for geothermal energy exploitation.

\section{REFERENCES}

Adeleye, D. (1974). Sedimentology of the fluvial bida sandstone (cretaceous), Nigeria. Sedimentary Geology, 12(1), 1-24. doi:https://doi.org/10.1016/0037-0738(74)90013-X

Adeniyi, J. (1985). Ground total magnetic intensity in parts of the Nupe Basin and the adjacent basement complex, Niger State, Nigeria. Niger J App Sci, 3, 67-78.

Aydın, I., \& Oksum, E. (2010). Exponential approach to estimate the Curie-temperature depth. Journal of Geophysics and Engineering 7(2), 113-125.

Bhattacharyya, B., \& Leu, L.-K. (1977). Spectral analysis of gravity and magnetic anomalies due to rectangular prismatic bodies. Geophysics, 42(1), 41-50.

Bhattacharyya, B., \& Leu, L. K. (1975). Analysis of magnetic anomalies over Yellowstone National Park: mapping of Curie point isothermal surface for geothermal reconnaissance. Journal of Geophysical Research, 80(32), 4461-4465.

Blakely, R. J. (1996). Potential theory in gravity and magnetic applications: Cambridge university press.

Jessop, A., Hobart, M., \& Sclater, J. (1976). The world heat flow data collection-1975, Geothermal Series. Ottawa: Geological Survey of Canada, Earth Physics Branch, Energetic Mines Resources.

Khojamli, A., Ardejani, F. D., Moradzadeh, A., Kalate, A. N., Kahoo, A. R., \& Porkhial, S. (2016). Estimation of Curie point depths and heat flow from Ardebil province, Iran, using aeromagnetic data. Arabian Journal of Geosciences, 9(5), 383.

Nwankwo, L. I., \& Shehu, A. T. (2015). Evaluation of Curie-point depths, geothermal gradients and nearsurface heat flow from high-resolution aeromagnetic (HRAM) data of the entire Sokoto Basin, Nigeria. Journal of Volcanology and Geothermal Research 305, 45-55. doi:https://doi.org/10.1016/j.jvolgeores.2015.09.017

Obaje, N. G. (2009). Geology and mineral resources of Nigeria (Vol. 120): Springer.

Obande, G. E., Lawal, K. M., \& Ahmed, L. A. (2014). Spectral analysis of aeromagnetic data for geothermal investigation of Wikki Warm Spring, north-east Nigeria. Geothermics, 50, 85-90.

Ochieng, L. (2014). Overview of geothermal surface exploration methods. Paper presented at the Short Course IX on Exploration for Geothermal Resources, Kenya.

Ojo, S. (1984). Middle Niger Basin revisited, magnetic constraints on gravity interpretations. Paper presented at the Nigerian Mining and Geosciences Society Conference, Nsukka, Nigeria, Nsukka, Nigeria.

Okubo, Y., Graf, R., Hansen, R., Ogawa, K., \& Tsu, H. (1985). Curie point depths of the island of Kyushu and surrounding areas, Japan. Geophysics, 50(3), 481-494.

Okwokwo, O. I., Adetona, A. A., Adewumi, T., \& Adeniran, S. O. (2018). Interpretation of high resolution aeromagnetic data to determine sedimentary thickness over part of Bida Basin, North Central Nigeria. Journal of Geology and Mining Research 10(6), 72-80.

Ross, H. E., Blakely, R. J., \& Zoback, M. D. (2006). Testing the use of aeromagnetic data for the determination of Curie depth in California. Geophysics, 71(5), L51-L59. 
Spector, A., \& Grant, F. (1970). Statistical models for interpreting aeromagnetic data. Geophysics, 35(2), 293-302.

Stampolidis, A., Kane, I., Tsokas, G., \& Tsourlos, P. (2005). Curie point depths of Albania inferred from ground total field magnetic data. Surveys in Geophysics, 26(4), 461-480.

Tanaka, A., Okubo, Y., \& Matsubayashi, O. (1999). Curie point depth based on spectrum analysis of the magnetic anomaly data in East and Southeast Asia. Tectonophysics, 306(3-4), 461-470.

Tselentis, G. (1991). An attempt to define Curie point depths in Greece from aeromagnetic and heat flow data. pure and applied geophysics 136(1), 87-101.

Udensi, E., \& Osazuwa, I. (2004). Spectral determination of depths to magnetic rocks under the Nupe Basin, Nigeria. Nigerian Association of Petroleum Explorationists Bulletin, 17, 2227. 